\title{
Ultrastructural and Morphological Alterations Induced by 23-4-A-CC on Promastigotes of Leishmania amazonensis
}

Rodolfo Bento Balbinot ${ }^{1 *}$, Danielle Lazarin-Bidóia ${ }^{1}$, Rayanne Regina Beltrame Machado ${ }^{1}$, Hélito Volpato $^{1}$, Michael Jackson Vieira da Silva ${ }^{2}$, Fernanda Andreia Rosa ${ }^{2}$, Tania Ueda-Nakamura ${ }^{1}$ and Celso Vataru Nakamura ${ }^{1}$

${ }^{1}$ Laboratório de Inovação Tecnológica no Desenvolvimento de Fármacos e Cosméticos, Departamento de Ciências Básicas da Saúde/Universidade Estadual de Maringá (UEM), Maringá, Paraná, Brazil.

${ }^{2}$ Departamento de Química/Universidade Estadual de Maringá (UEM), Maringá, Paraná, Brazil. *Corresponding author: rodolfobalbinot@hotmail.com

Leishmania amazonensis is the principal protozoan that causes cutaneous leishmaniasis and affects approximately 12 million people worldwide. Current therapies available have variable efficacy and high toxicity. In this context, are necessary studies for the development of new alternatives of treatment for leishmaniasis [1][2]. In previous studies, our research group has already shown that the synthetic compound 3-carboxyethyl-1-phenyl-4-\{[(fluorophenyl)amino]methyl $\}-5$-(4-nitrophenyl)-1Hpyrazole (23-4-A-CC) showed an $\mathrm{IC}_{50}$ of $3.8 \mu \mathrm{M}$ after $72 \mathrm{~h}$ of treatment. The aim of this study was to evaluate ultrastructural and morphological alterations in L. amazonensis promastigotes. For this, promastigotes treated with $\mathrm{IC}_{50}$ of $\mathbf{2 3 - 4}-\mathbf{A}-\mathbf{C C}$ for $72 \mathrm{~h}$, were fixed in $2.5 \%$ glutaraldehyde in $0.1 \mathrm{M}$ cacodylate buffer for $24 \mathrm{~h}$ at $4{ }^{\circ} \mathrm{C}$. For SEM, the parasites were dehydrated, critical point-dried in $\mathrm{CO}_{2}$, sputter-coated with gold and observed using a FEI Scios. For TEM, parasites were postfixed, dehydrated, embedded in Polybed 812 resin, obtained ultrathin sections, contrasted with uranyl acetate and lead citrate, and observed in JEOL JEM 1400. To evaluate the appearance of lipids bodies, the parasites were probed with Nile red and observed in confocal microscopy Zeiss LSM 5 Pascal. Our results demonstrated that 23-4-A-CC induced morphological and ultrastructural changes, such as mitochondrial swelling, presence of lipid storage bodies and abnormalities in flagellum. Our results support further studies and may open the way for the development of new chemotherapeutic agents against L. amazonensis [3].

\section{References:}

[1] T.F. Stefanello et al., AAC, 58 (2014), p. 7112.

[2] L.T. Tonin et al., Pharmacotherapy, 64 (2010), p. 386.

[3] The authors acknowledge founding from CAPES, CNPq, COMCAP-UEM, FINEP and PRONEX/Fundação Araucária. 

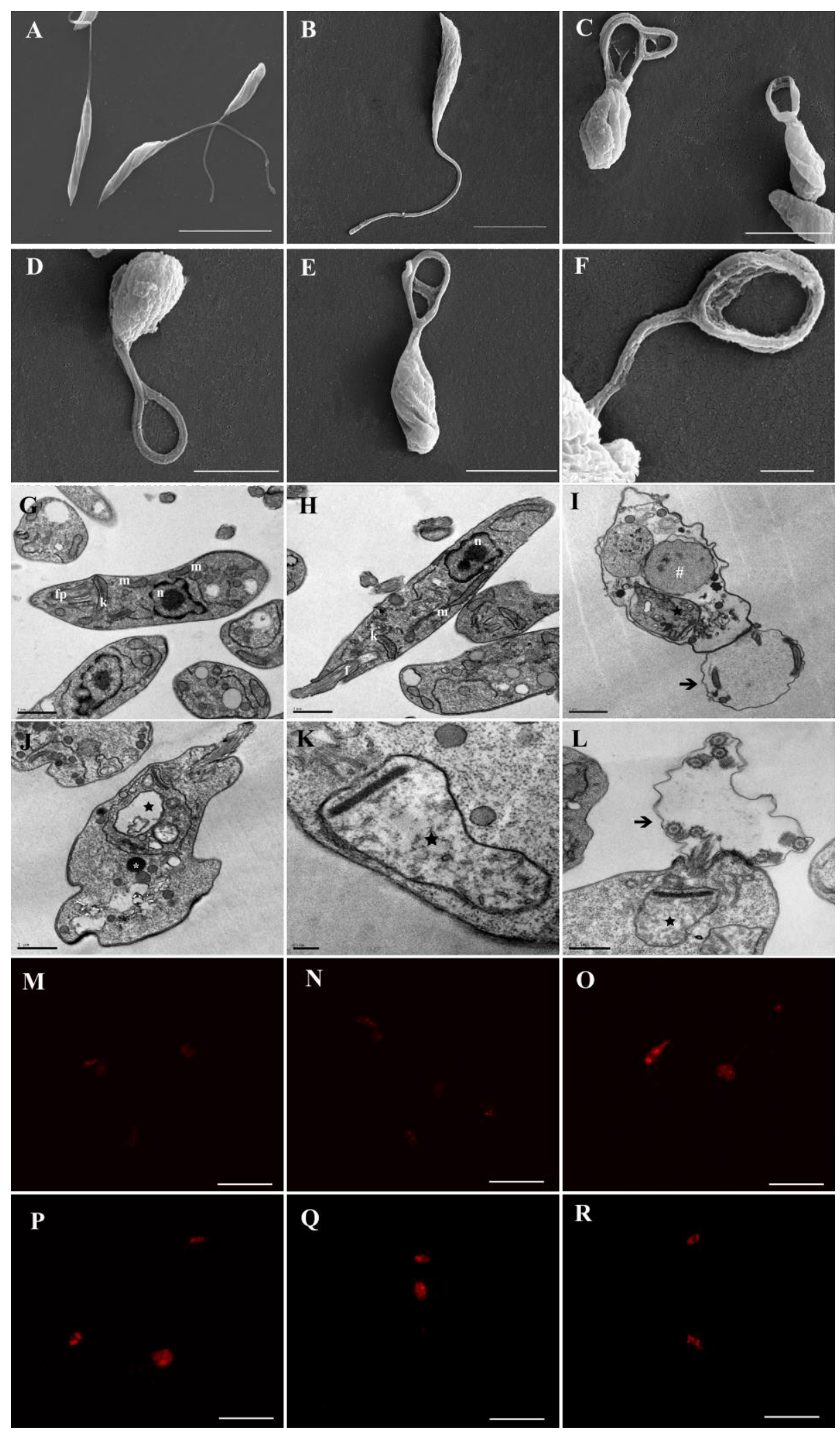

$\mathbf{O}$

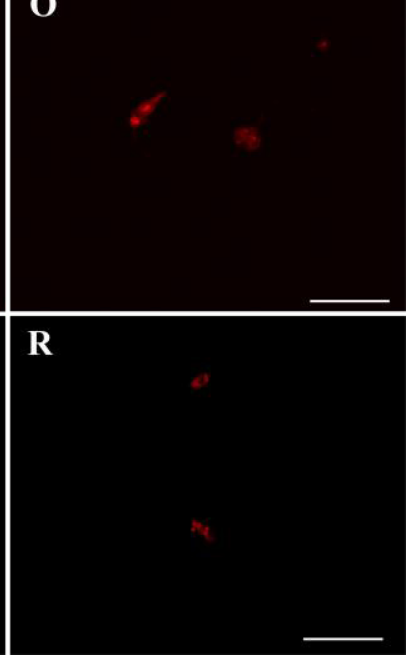

Figure 1. Morphological and ultrastructural alterations in promastigote forms of Leishmania amazonensis treated with $3.8 \mu \mathrm{M}$ of 23-4-A-CC for $72 \mathrm{~h}$. (A-F) SEM images. (G-L) TEM images. (M-R) Nile red confocal microscopy images. (A-B, G-H, M-N) Untreated promastigotes. (C-F, I-L, O-R) Promastigotes treated with $3.80 \mu \mathrm{M}$ of 23-4-A-CC. (\#) DNA disorganization in nuclei; (*) lipids bodies; (star) mitochondrial swelling in the kinetoplast region; (arrow) flagellum disorganization; (f) flagellum; (fp) flagellar pocket; (k) kinetoplast; (m) mitochondrion; (n) nucleus. Scale bars $=20 \mu \mathrm{m}$ in $\mathrm{A}, \mathrm{M}-\mathrm{R} ; 5 \mu \mathrm{m}$ in $\mathrm{B} ; 4 \mu \mathrm{m}$ in $\mathrm{C}, \mathrm{E} ; 3 \mu \mathrm{m}$ in $\mathrm{D} ; 1 \mu \mathrm{m}$ in F-J; $0.5 \mu \mathrm{m}$ in K-L. 